\title{
0 enunciado do cinema como inovação pedagógica da prática educativa escolar brasileira
}

\author{
The cinema's enunciation as a pedagogical innovation \\ of Brazilian educational practice
}

El enunciado del cine como innovación pedagógica de

la práctica educativa escolar brasileña

ERENILDO JoÃo CARLOS (iDa

\section{Resumo}

Esse ensaio registra algumas reflexões sobre o cinema, como um dispositivo pedagógico inovador da prática educativa escolar brasileira. Tomando como fonte de investigação alguns de escritos de época e outros, correlacionados ao assunto, busquei analisar a questão, a partir do pressuposto teórico-metodológico da Análise Arqueológica do Discurso (AAD). Os achados indicam que o objeto-enunciado do cinema, como inovação pedagógica da prática educativa escolar brasileira, apareceu, histórica e discursivamente, no início do século XX. Esse acontecimento suscitou, de um lado, a produção e a proliferação de diversos dizeres sobre ele, oriundos de instancias sociais e distintos domínios do saber; de outro, a tessitura de uma formação discursiva especifica sobre o nexo entre educação e cinema, sintetizado na expressão cinema educativo.

Palavras-chave: Inovação pedagógica escolar. Cinema educativo. Discurso. Análise Arqueológica do Discurso.

\footnotetext{
a Universidade Federal da Paraíba (UFPB), João Pessoa, PB, Brasil. Doutor em Educação, e-mail: erenildojc@hotmail.com
} 


\begin{abstract}
This essay registers some reflections on the cinema, as an innovative pedagogical device of the Brazilian educational practice. Taking as a source of investigation some of the periodicals and others, correlated to the subject, I sought to analyze the question from the theoretical-methodological presupposition of the Archaeological Analysis of Discourse (ADA). The findings indicate that the object-enunciation of cinema, as a pedagogical innovation of Brazilian educational practice, appeared, historically and discursively, at the beginning of the 20th century. On the one hand, this event provoked, on the one hand, the production and the proliferation of diverse sayings about him, originating from social instances and different domains of knowledge; on the other hand, the tessitura of a specific discursive formation on the nexus between education and cinema, synthesized in the expression educational cinema.
\end{abstract}

Keywords: School pedagogical innovation. Educational cinema. Speech. Archaeological Analysis of Speech.

\title{
Resumen
}

Este ensayo registra algunas reflexiones sobre el cine, como un dispositivo pedagógico innovador de la práctica educativa escolar brasileña. Tomando como fuente de investigación algunos de escritos de época y otros, correlacionados al asunto, busqué analizar la cuestión, a partir del supuesto teórico-metodológico del Análisis Arqueológico del Discurso (AAD). Los hallazgos indican que el objeto-enunciado del cine, como innovación pedagógica de la práctica educativa escolar brasileña, apareció, histórica y discursivamente, al início del siglo XX. Este acontecimiento suscitó, por un lado, la producción y la proliferación de diversos dones sobre él, oriundos de instancias sociales y distintos dominios del saber; de otro, la tesitura de una formación discursiva específica sobre el nexo entre educación y cine, sintetizado en la expresión cine educativo.

Palabras clave: Innovación pedagógica escolar. Cine educativo. Discurso. El análisis arqueológico del discurso.

\section{Introdução}

Chegamos ao século XXI compartilhando a premissa de que vivemos em um tempo histórico-social marcado pelo domínio do cultural (SANTOS, 1996; THOMPSON, 1995; JAMESON, 1996, SILVA, 1999) e do visual (BARTHES, 2005; AUMONT, 20012 SANTAELA e NOTH, 2005). Essa discussão ganhou força nos meados do século passado, a partir dos movimentos culturais literários e 
artísticos, estendendo-se, posteriormente, a outros campos, como o da arquitetura, do design, da paisagem urbana e da indústria cultural cinematográfica.

Desde então, inúmeras evidências históricas e argumentos razoáveis foram apresentados; várias teorias foram produzidas e dizeres foram escritos e pronunciados sobre esse acontecimento, formulados por pessoas ocupadas em tratar desse assunto, de uma maneira mais elaborada e científica, o que conferiu visibilidade à questão e incitou o reconhecimento favorável de sua relevância social e histórica.

No seio dessa nova paisagem, foi-se desenhando uma dimensão da cultura constituída visualmente, ou seja, uma região cujos contornos e conteúdo apontavam a existência do visual como uma dominante cultural na organização e no funcionamento societário contemporâneo; e da imagem visual, como uma de suas variantes estruturantes. Em função disso, emergiu um fervoroso debate, que desencadeou uma série de reflexões, estudos e discursos sobre a possibilidade da imagem visual, de seus gêneros e funcionamentos se configurarem como uma esfera da cultura visual específica, produtora de um modo de se pensar, se dizer e de se fazer a cultura visual imageticamente.

No borbulho desse movimento, a problemática da imagem cinematográfica ocupou um lugar considerável. Não somente por conta da novidade e representação de status e glamour social que, de certa maneira, simbolizava o prestígio e o poder das classes médias e altas da sociedade; mas, sobretudo, por conta de que a imagem cinematográfica operou uma transformação profunda na própria lógica e funcionamento da imagem clássica, deslocando a fixidez dos significantes visuais para a fluidez do movimento; o trabalho criativo e corpóreo direto das mãos e do olho do artesão solitário para o suporte tecnológico da câmara do cineasta e de sua equipe.

Esse acontecimento singular da história da cultura visual provocou um grande impacto sobre o olho e a consciência dos receptores da imagem. Em outros termos, o faz de conta da linguagem e do funcionamento da imagem cinematográfica, emergente a partir do fim do século XIX, com o aparecer dos primeiros cinematógrafos, atingira profunda e simultaneamente os cinéfilos em sua cognição e emoção, em sua racionalidade e sensibilidade, ao codificar ideologias, 
representar valores, veicular concepções de mundo, seduzir ao consumo de estilos de vida e de mercadorias, desconstruir a concepção de tempo linear, ao proporcionar a visualização, no tempo presente, da simultaneidade do passado e do futuro.

Graças a essa combinação de realidades e de ilusões, de espetáculos e de cotidianidades, de existências e de ficções, de mitos e de histórias, de fantasias e de verdades, o cinema encanta, prende a atenção, alegra e entristece, faz rir e chorar, gera esperanças e medos, expõe, enfim, a finitude e a plenitude da condição humana com um poder de convencimento capaz de superar, até mesmo, um tratado de filosofia e outros gêneros visuais imagéticos.

Com efeito, a riqueza do faz de conta da linguagem cinematográfica (MARTIN, 2003) carrega um universo de possibilidades estéticas, ideológicas, epistemológicas, mercadológicas e educativas, que superou o modo de existência de outras formas de imagens visuais. No seio desse movimento geral, de um lado, da cultura e, de outro, da cultura visual, que identificamos, precisamente, o aparecimento e a constituição de uma ordem discursiva particular que posiciona o cinema, não somente como modo próprio de cultivo e reprodução da cultura visual, mas também, como um dispositivo pedagógico inovador da prática educativa.

Ao escavar o assunto em tela, deparo-me com a necessidade preliminar de fazer alguns esclarecimentos que, no cerne dessa análise, funcionam como pressupostos da linha de argumentação realizada e que, por isso, pode indicar os contornos do lugar em que essa reflexão se situa, ao pensar a questão que me proponho a examinar, no âmbito do debate contemporâneo sobre a relação triádica entre cultura visual — imagem visual — cinema (CARLOS, 2008). Sinto, portanto, a necessidade de por algumas ideias em seus devidos lugares por considerar que o reconhecimento da cultura, funcionando como um constituinte da sociabilidade humana, tem sido tratada de diferentes maneiras.

\section{Preliminares sobre a questão em tela}

O debate contemporâneo sobre a cultura põe em circulação uma variedade de modos de dizê-la, faz aparecer uma profusão de discursos sobre a cultura, em 
geral; a visual imagética, em particular; e a cinematográfica, em especial. O que me leva a entender que dizer cultura, como uma constituinte fundamental da paisagem contemporânea, guarda, de um lado, uma gama de significados singulares, distintos um do outro; de outro, a existência de uma série de íntimas conexões entre eles.

Pensemos nos casos das expressões correntes cultura visual (HERNANDEZ, 2007), estudos culturais (SILVA, 1999) e dominante cultural (JAMESON, 1996). A princípio observa-se, pela leitura ou pronúncia dessas expressões, que estas carregam um significante e um sentido comum, qual seja, o de que elas dizem algo sobre a cultura, sobre esse complexo social particular do mundo humano, não sobre a esfera ontológica da natureza (PINTO, 1979; LESSA, 2007; LUCÁKS, 2010), propriamente dita, cujo aparecimento e funcionamento são regidos por determinações que não foram inventadas pelos seres humanos. Em suma, elas codificam modos determinadas de discorrer sobre a cultura.

Assim sendo, enquanto elemento substantivo das três expressões, o termo cultura seria uma palavra designativa de um acontecimento ou uma realidade objetiva, produzida pelo seres humanos, no seio mesmo da natureza, a fim de responder e atender suas necessidades naturais, socioculturais e pessoais, postas no contexto das relações que os homens estabelecem entre si, com a natureza, com os processos sociais de produção da cultura e com os produtos culturais, advindos dessa relação existencial e histórica.

Contudo, não obstante a cultura aparecer como um significante comum nas referidas noções, ocorre também a presença de uma série de aspectos semânticos, epistêmicos e histórico-culturais, distintos em cada uma dessas expressões. Dito de outra maneira, embora do ponto de vista da composição dos significados ligados aos significantes das expressões cultura visual, estudos culturais e dominante cultural, as três noções se ocupam com a questão da cultura. Uma investigação mais acurada sobre cada uma apontaria uma correlação entre significados específicos e distintos, seja por conta de que suas composições conceituais visam representar e explicitar diferentes aspectos da paisagem sociohistórica; seja por conta de que suas formulações contemplam conteúdos de natureza epistemológicas, filiados originariamente a distintos domínios do saber elaborado. 
Em função disso, pode-se dizer que cada uma das expressões mencionadas conserva conteúdos semânticos próprios, os quais não devem ser confundidos um com o outro, pelo simples fato de que representam algum aspecto do complexo social. Vejamos, resumidamente, cada um desses modos de dizer o acontecimento estruturante da cultura na sociabilidade contemporânea, no seio da ordem de nossa reflexão analítico argumentativa, a fim de entendemos o domínio do visual e, em seu seio, a problemática de nosso interesse, a saber, o discurso da imagem cinematográfica como inovação pedagógica da educação escolar.

Comecemos com o significante dominante cultural. De modo geral, parece-me que essa noção não se refere exclusivamente ao papel da cultura na constituição da humanidade do homem, de seu modo distinto de existir socialmente e de organizar suas relações sociais ao longo de sua trajetória histórica no planeta, conforme concebe o modo clássico de entendimento da cultura. Enquanto o resultado da atividade humana é algo próprio da espécie humana, o termo cultura representa uma visão antrofilosofica da questão, própria da ontologia do ser social, como diria Lukács (2010). Por sua vez, a expressão dominante cultural aciona uma série de outros significados e sentidos, comprometidos prioritariamente em dizer algo específico sobre a cultura, em assinalar alguns aspectos peculiares de sua presença e envolvimento na organização do tempo presente da sociedade tardia.

Em outros termos, a noção dominante cultural (JAMESON, 1996) confere visibilidade ao status assumido pela cultura no estágio contemporâneo da economia capitalista, indicando, assim, de um lado, sua posição fundante na ordem geral da economia; de outro, um corte temporal, uma espécie de delimitação das coisas ditas sobre seu funcionamento no contexto social da história presente.

Nessa paisagem tardia, o cultural teria um peso fundamental, representado pelo termo dominante, o qual imprime o reconhecimento do cultural não somente como uma dimensão própria da existência genérica e abstrata do ser humano, seja no que se refere à particularidade de sua configuração, seja no que diz respeito a seu modo de funcionamento peculiar enquanto complexo social, mas, sobretudo, como uma característica fundante do modo como as relações sociais vigentes são produzidas e reproduzidas. Nessa ótica, seria por meio da cultura que se concebe, se explica, se diz e se faz a própria história do tempo presente; se constitui a 
diversidade de modos subjetivos e objetivos de vida, individual e coletivo, local e global contemporânea.

A meu sentir, esse entendimento ratificou o campo de investigação que pode ser sinteticamente representado, na atualidade, por meio da expressão estudos culturais, cujo fim seria o de se debruçar sobre diferentes acontecimentos e artefatos culturais, situando-se em qualquer domínio do saber elaborado, a fim de conhecê-lo, sejam eles artefatos culturais visuais ou não.

O interessante dessa visão se encontra no fato de que ela abarca, de um lado, qualquer objeto cultural, de outro, qualquer gênero do saber elaborado que eleja o cultural, enquanto produção humana, como objeto de sua pesquisa, estudo ou reflexão sistemática, inclusive aqueles objetos e domínios que gradativamente os Estudos Culturais se distanciaram, no percurso de seu aparecimento e formação, enquanto campo de estudos da cultura.

Sabe-se que o legado dos Estudos Culturais é bem recente (SCHULMAN, 1999). Este legado tem cerca de 70 anos, desde a criação do Center Contemporary Cultural Studies, por Richard Hoggart, em 1958. Embora ainda não tenha um século, os Estudos Culturais vêm operando uma série de mudanças significativas no entendimento e na pesquisa sobre a questão da cultura, desde que surgiu na Inglaterra, na década de 1950, através das investigações de seus precursores, conforme esclarece Escosteguy (1999, p. 139) em seu texto Estudos Culturais: uma introdução. Nesse escrito, informa a autora:

Na realidade são três os textos, surgidos nos fins dos anos 50, que estabeleceram as bases dos Estudos Culturais: Richard Hoggart com The uses of literacy (1957), Raymond Williams com Culture and society (1958) e E. P. Tompson com The marking of de english workingclasse (1963).

$\mathrm{Na}$ realidade são três os textos, datados do final dos anos 50, que estabeleceram as bases dos Estudos Culturais: Richard Hoggart com The uses of literacy (1957), Raymond Williams com Culture and society (1958) e. P. Tompson com The marking of de english working-classe (1963).

É obvio que não cabe e nem há condições, aqui, no espaço de um texto como esse, de retomar a trajetória dos Estudos Culturais. Interessa-me, tão somente, destacar desta história dois acontecimentos relevantes para as reflexões que empreendo neste escrito. O primeiro consiste no distanciamento gradativo dos 
Estudos Culturais das abordagens de cunho marxista, no que tange especificamente à visão genérico-abstrato da cultura, afeita ao caráter ontológico do gênero humano.

O segundo refere-se à rejeição ou ressignificação da clássica dicotomia cultura erudita x popular, característica de uma visão de mundo esquizofrênica, que buscou definir ideologicamente a legitimidade do que deveria ser ou não o cultural. Tal dicotomia seria própria de sociedades regidas pelo poder simbólico exercido pelos grupos e classes dominantes econômica, política e religiosamente.

O acontecimento do deslocamento do eixo do abstrato genérico para o concreto e da visão preconceituosa das elites aristocráticas e burguesas para a diversidade das práticas sociais, operada pelos Estudos Culturais, ampliou o leque de possibilidades de artefatos culturais a serem tratados como objeto da apreciação, estudo e investigação do referido campo, incluindo também no rol de seus interesses as práticas culturais vivenciadas cotidianamente pelos assim chamados grupos marginalizados.

Desse universo mais amplo do cultural, na perspectiva dos Estudos Culturais, ressalto a presença dos artefatos visuais, propriamente ditos, como constituintes, não somente da cultura em geral, mas dos objetos de interesse dos Estudos Culturais. O que, a meu ver, justifica-se pela presença pujante de um modo concreto e singular da cultura aparecer e funcionar, a saber, o visual. Nesse contexto de nossa reflexão, parece-me significativo a expressão cultura visual, vez que ela serve de indicativo dos estudos de uma região especifica da cultura.

Sob esse ponto de vista, pode-se dizer que a expressão cultura visual codifica e delimita, no conjunto geral da própria cultura, uma esfera particular, uma espécie de território desenhado pelos contornos de uma linha divisória demarcada, predominantemente, por processos, acontecimentos e artefatos visuais estruturantes do complexo social da cultura em geral e das próprias maneiras de organizar as formações societárias contemporâneas.

Assim, diria que, enquanto o significante dominante opera um recorte na ordem geral da sociabilidade humana, apresentando o cultural como um complexo social fundante de sua organização, o significante visual realiza um movimento de corte no interior da própria cultura, apontando e conferindo nela o visual, como um território, uma região ou uma camada relevante do complexo social da cultura. 
Nesse sentido, entendo que a noção de cultura visual, indica a peculiaridade de um duplo aspecto em sua composição: de um lado, conserva sua correlação afeita aos processos e resultados da atividade humana, codificado no termo cultura, como uma categoria geral que abrange toda a produção humana e exclui, logicamente, a natureza em si, ou seja, o conjunto de acontecimentos ecológicos, de processos biofísicos, resultantes e constituintes das dinâmicas eventuais e regulares, associadas à objetividade da vida no planeta; de outro, refere-se a um modo peculiar da cultura existir e funcionar, isto é, um modo visual, não a outros possíveis gêneros culturais, tais como o sonoro, o olfativo, o gustativa ou o tátil.

Esse duplo movimento contemplado na noção de cultura visual é importante na linha de argumentação que empreendo, pois evidencia que o adjetivo visual recorre tanto a uma restrição semântica, quanto a um corte epistemológico, indicando, assim, um limiar existencial e histórico no substantivo cultura, cujos limites seriam definidos pelo critério tricotômico da sensação-visão-olho. Assim, tudo que escape, tudo que fuja, tudo que não possa ser mostrado e visto de alguma maneira, em algum tempo e lugar determinado, não seriam objetos de interesse da cultura visual.

A expressão cultura visual incluiria, portanto, todos os artefatos culturais produzidos pelos seres humanos, passíveis de serem vistos, capturados por meio da retina, do olho. Em outros termos, o visual seria constituído pelo conjunto de processos, acontecimentos e artefatos que existam, tenham presença e possam ser vistos, percebidos, entendidos e abordados enquanto tais. Trata-se de toda produção humana que seja capturada pela mediação tricotômica da sensação-visão-olho, toda produção visual humana, a exemplo do artesanato, da escultura, da arquitetura, da paisagem e do design; ou da dança, dos gestos e da escrita; ou, ainda, do desenho, da pintura, da fotografia, da infoimagens e do cinema, gêneros da imagem visual que tocaremos agora, antes de adentrarmos na questão da relação cinema e educação, pelo viés do discurso. 


\section{A imagem visual na cultura contemporânea}

A discussão precedente acerca dos significantes dominante cultural, estudos culturais e cultura visual carregam, uns menos, outros mais, a problemática do acontecimento da imagem visual na paisagem cultural contemporânea (BARTHES, 2005; AUMONT, 2012; SANTAELLA, 2005; CARLOS, 2008, 2010, 2011).

Com efeito, ao debruçar-me sobre esse assunto, noto que a presença e o funcionamento da imagem visual, no estágio atual da sociabilidade humana, é indiscutível. Indubitavelmente, a evidência desse acontecimento se faz perceber de modo capilar, diverso e multifuncional. Capilar porque alcança, graças aos suportes das novas tecnologias, os mais distantes e impensáveis lugares do planeta, situações e circunstâncias, práticas e trabalhos sociais, instituições e indivíduos. Diverso porque contempla vários gêneros visuais, dos clássicos aos pós-modernos. Multifuncional porque cumpre uma variedade de finalidades: afeta a intimidade e a privacidade das pessoas simples e de prestígio social; representa visualmente ideologias dos mais variados tipos; seduz o indivíduo ao consumo de produtos e serviços; associa-se a interesses políticos e religiosos locais, nacionais e globais; embeleza e estetiza os espaços domésticos, privados e públicos; emprega-se intencionalmente como um dispositivo educativo para distintos espaços sociais de aprendizagem, dentre outros fins.

Provavelmente, por conta dos diversos modos de sua existência, de suas diferentes possibilidades culturais e de suas funções sociais estruturantes, na dinâmica da vida cotidiana, no governo dos indivíduos, na formação da subjetividade e no funcionamento, Barthes (2005) afirmou que vivemos sob a égide de uma civilização da imagem.

Considerando a imagem visual como acontecimento cultural e histórico familiar, seu reconhecimento torna-se irrefutável. Diríamos: uma obviedade. Entretanto, como o óbvio nem sempre é tão obvio como aparenta ser, e como o simples saber de experiência não é suficiente para se conhecer, com propriedade, determinados objetos familiares, a imagem visual foi erigida ao status de objeto de reflexão, estudo e pesquisas de muitas pessoas comuns e profissionais, a exemplo 
dos pedagogos e educadores em geral, situados em diferentes domínios do saber elaborado.

Assim, a imagem visual se torna, por essas e outras razões, um artefato cultural desejado, disputado, analisado, problematizado, criticado e pesquisado; a ponto de incitar e instaurar um novo campo de saber e de poder; poderia se dizer uma espécie de dominante cultural no seio da cultura visual tardia. Esse acontecimento tem exigido tanto o emprego consciente, quanto a investigação cuidadosa, metódica e competentemente da imagem visual em seus diferentes contextos.

Com efeito, dizer algo sobre a cultural visual imagética de maneira fundamentada, assentada no conhecimento de causa, passou a ser não somente fruto da curiosidade de um ou de outro interessado no assunto, mas uma necessidade, instaurada no seio do funcionamento da cultura visual contemporânea, que transbordou do lugar comum das artes visuais propriamente dita, ou seja, do lugar comum dos saberes e dos dizeres produzidos e difundidos por seus profissionais, produtores e educadores visuais; afetando outros espaços, a curiosidade e o campo de atuação discursivo, teórico e prático de outros sujeitos sociais que se ocupam, direta ou indiretamente, com o ser humano, seja no que tange a sua formação de sujeitos específicos, seja no que diz respeito à produção, circulação e ao consumo de produtos e serviços visuais destinados a afetá-lo intencionalmente em determinados sentidos sociais.

Em outros termos, numa sociedade onde o visual não assume somente uma posição de objeto de consumo, mas sobretudo uma função estratégica de constituição da objetividade e subjetividades das relações sociais capitalistas. Ocupar-se com a problemática da imagem passou a ser, certamente, uma atividade necessária em uma sociedade que erige, dentre outros aspectos, a imagem visual como um dos constituintes da organização das relações sociais vigentes e do governo dos homens.

Nesse canário é perfeitamente compreensivo que a imagem visual seja uma espécie de força produtiva, de dominante cultural, implicada com a feitura e a reprodução da economia capitalistas; seja um artefato mercadoria produzido para ser consumido, gerador de lucro e de riqueza, posto no mercado cultural para ser comprado e vendido como qualquer outra mercadoria; seja por ser um objeto que 
seduz, emociona, significa e representa e que, por isso mesmo, deva ser mostrado, visto, contemplado, admirado e posto em circulação; seja por conta de que carrega matizes ideológicas hegemônicas ou de minorias relevantes, que afeta simbolicamente pessoas em sua singularidade familiar e cotidianidade; e a população em geral, situada em lugares e tempos sociais distintos da história presente.

Esse acontecimento não é difícil de ser conferido. Basta lançarmos um olhar sobre a paisagem contemporânea da cultura visual que capturamos, através de nossa retina, há a presença de uma variedade de gêneros imagéticos, dentre os quais o cinematográfico, o qual entendo como exemplar, do caráter produtivo, capilar e funcional da imagem visual. Eu diria, que tal como as demais, a imagem fílmica instaurou uma história própria, desenvolveu uma linguagem específica, criou novas possibilidades do exercer o poder visual imagético, impossíveis de serem cogitados e efetivados através dos gêneros clássicos de imagem, a exemplo do desenho, da pintura e da própria fotografia.

Nesse sentido, não seria exagero dizer que o filme, como produto da indústria cultural cinematográfica, revolucionou a história da imagem, fez aparecer um modo de mostrar visualmente as coisas jamais imaginado antes. De modo que, a linguagem do cinema poderia ser vista como um divisor de águas no interior do movimento da cultura visual imagética. $O$ que, como não poderia deixar de acontecer, acabou atingindo profundamente os espaços sociais de aprendizagens intencionais, a exemplo da escola, afetando, por conseguinte, os que pensam e os que realizam seu trabalho educativo.

Nesse sentido, se observarmos mais cuidadosa e curiosamente, movido pelo desejo de entender e investigar o artefato cultural da imagem fílmica, como um aspecto das possíveis relações entre educação e visualidade na sociedade contemporânea, nos surpreenderemos com vasta produção, consumo e proliferação de dizeres pedagógicos sobre a questão, expressos em saberes, teorias e modos de operar a linguagem visual cinematográfica. Saberes estes produzidos por diferentes sujeitos, situados em diferentes lugares e instâncias, registrados em diferentes modalidades e fontes, a exemplo de livros, revistas, dissertações, teses, pronunciamentos, normas jurídicas, instituições, veículos de comunicação de massa, tais como a televisão, a internet e o celular. 
Consta-se, portanto, que o encantamento relativo à linguagem cinematográfica, as possibilidades de seus usos educativos e pedagógicos passaram a ser objetos de interesse dos profissionais da área da educação e das pessoas envolvidas. O que desencadeou na realidade da educação brasileira uma série de ações e preocupações, uma profusão de usos, propostas e investigações sobre o nexo entre educação e cinema. De modo que o acontecimento do cinema na educação acabou se tornando não somente um objeto do desejo e da disputa de certos profissionais da educação; mas também uma esperança de inovação da prática educativa escolar. Figurando, assim, como um acontecimento sobre o qual o discurso pedagógico brasileiro passou a dizer algo.

\section{0 dispositivo pedagógico inovador do cinema como objeto do discurso}

Em conformidade com o que tenho argumentado, entendo ser perfeitamente possível, no interior da cultura em geral e da cultura visual em particular, o aparecimento de inúmeras perguntas sobre a existência do cinema e de seus usos educativos na escola (FORQUIM, 1993). Perguntas que podem se ocupar, evidentemente, de inquerir sobre aspectos pertinentes ao nexo entre os dois termos mencionados antes, o qual pode ser abordado e dito de maneiras diversas, a depender do lugar em que se situam os sujeitos indagadores.

Aqui, não questiono o acontecimento efetivo do nexo entre o artefato cultural visual imagético do cinema e seu uso educativo na escola, mas, precisamente, o discurso de que o cinema com sua linguagem revolucionária trouxe uma inovação para a educação escolar brasileira.

Ora, penso que essa questão que coloco exige de mim o reconhecimento da emergência e da constituição de um campo de investigações que contempla a possibilidade da análise e da investigação do acontecimento do discurso, seja da relação ao vínculo entre cultura, cultura visual e imagem visual, seja em relação ao nexo específico entre educação e cinema. Sobre isso, cabem algumas palavras.

Considerando o que foi dito no tópico anterior, entendo que, embora não seja identificado como um campo da investigação situado rigorosamente no 
horizonte epistemológico dos estudos culturais, vez que sua filiação pode ser localizada no horizonte dos estudos empreendidos no domínio geral do saber, registrado pela rubrica análise do discurso, as análises do discurso também se debruçam sobre a cultura humana, seja ela visual ou não, já que não seria adequado conceber o discurso sobre alguma coisa, como algo natural, como algo produzido pelo determinismo das leis naturais, tais como o pôr do sol, as fases da lua, do tempo natural do plantio e da colheita. Ou, ainda, como algo somente ligado aos dizeres eruditos e aos pronunciamentos esquizofrênicos e preconceituosos de representantes dos grupos e classes dominante e/ou hegemônicos da sociedade.

Nesse horizonte argumentativo, dizer discurso significa dizer, necessariamente, cultura, já que o discurso é, em última instância, produto da atividade humana. Entretanto, embora seja um artefato do mundo da cultura em geral, o significante discurso informa acerca da existência de uma esfera, uma região, um território cultural próprio, constituído pelo signo, seu funcionamento, suas representações simbólicas e coisas efetivamente ditas por seu intermédio. Desse modo, o discurso entendido como algo cultivado, produzido, carregaria, como qualquer outro artefato da cultura humana, propriedades, aspectos e funcionamentos peculiares.

Se concordamos que a cultura pode ser entendida e abordada de modos diferentes, conforme mencionamos no tópico anterior, o discurso, evidentemente, também. Exemplo disso, seria a perspectiva da análise arqueológica do discurso, a que assumo aqui. Para ela, o discurso se encontra, de um lado, situado no terreno na linguagem; de outro, caracteriza-se por configurações próprias do nível enunciativo, as quais são constituídas pelo universo de todos os artefatos, acontecimentos, modos de funcionamentos, apropriações e usos típicos do modo de existência dos objetos presentes no duplo feixe de relações expressos no par discurso-enunciado (FOUCAULT, 1999, 2000; ALCANTARA, CARLOS, 2013; CARLOS, 2017).

Nessa linha de entendimento, pode-se dizer que os estudos arqueológicos encontram seus objetos de reflexão, de investigação e de pesquisa, na camada da cultura em que se encontram as coisas efetivamente ditas, postas em circulação. Nessa camada do dizer, situa-se o nível do discurso-enunciado e seu arquivo. Em outros termos, arqueologicamente diz-se que o conjunto dos acontecimentos 
discursivo-enunciativos existentes, disponíveis e utilizáveis, regulado por determinadas práticas discursivas, compõe o arquivo arqueológico.

Assim concebido, o arquivo seria constituído pelo conjunto das coisas ditas, ou seja, da gama de artefatos discursivos existentes, bem como pelo universo dos modos, campos associativos e posições possíveis de se dizer algo sobre alguma coisa, ou seja, de apropriações e empregos dos enunciados, postos na formação discursiva de determinados feixes de relações, anônimos e históricos, denominados de práticas discursivas (FOUCAULT, 2000).

Considerando esse pressuposto, entendo que uma das maneiras de abordar a questão do cinema e de sua relação com educação, enquanto prática social específica, encontra-se em identificá-la, descrevê-la, problematizá-la e posicioná-la, como um dispositivo pedagógico inovador da prática educativa escolar, no nível da existência do discurso-enunciado ${ }^{2}$. As razões são óbvias e já foram expostas anteriormente, ou seja, o aparecimento e consolidação da imagem cinematográfica e seus usos educativos no cenário da cultura visual contemporânea é evidente. Uma evidência não somente empírica, mas discursiva.

Assim, identifico que em meio à população de coisas ditas sobre o cinema, sua linguagem e seu modo próprio de lidar com a representação visual, aparece a visão do cinema educativo enquanto uma espécie de prática pedagógica inovadora.

\section{Elementos discursivos sobre o cinema como dispositivo pedagógico inovador}

Do ponto de vista arqueológico em que analiso a relação educação e cinema, e, mais especificamente, a questão do cinema como dispositivo pedagógico inovador, a assertiva, expressada na questão formulada, é tratada como um discursoenunciado. Abordar a questão enquanto tal, exige, que ela seja examinada de modo a

\footnotetext{
${ }^{2}$ Para exemplificar essa questão, ler: BARQUETE, Felipe Leal. $O$ discurso da criação fílmica como mediação do saber escolar. 2017. 134f. Dissertação (Mestrado em Educação) - UFPB, João Pessoa. Disponível <file:///F:/Users/Admin/Downloads/DISSERTAO_FELIPE_LEAL_BARQUETE_PPGE_UFPB.pdf>. Acesso em: 08 mar. 2019.
} 
descrever e conferir visibilidade aos elementos especificamente enunciativos, constituintes de sua existência.

Como a descrição e a explicitação desses elementos arqueológicos do discurso exigem uma investigação mais acurada e demorada, dado a complexidade das múltiplas relações, correlatos e derivações que estão envolvidas na constituição do caso particular do enunciado referente ao cinema como um dispositivo pedagógico inovador, limito-me, nesse ensaio, a trazer luz tão-somente a alguns feixes dessas conexões, tendo em vista problematizar e discutir o objeto anunciado no contexto do debate da educação contemporânea, ocupada com esse assunto.

Tal como a questão foi formulada, pode-se dizer que alguns aspectos são apresentados como objetos constituintes de minha análise, quais sejam: a) a noção corrente de inovação, articulada às mudanças culturais proporcionadas pela utilização de certas invenções; b) o aparecimento do cinema como exemplo de inovação cultural no campo da cultura visual; c) e o filme como inovação pedagógica da educação escolar.

A ideia geral de que o cinema proporcionaria à educação algo de novo, apresenta-se como significativa; e o indício dessa possibilidade se encontra codificado no significante inovação. Na perspectiva analítica de cunho arqueológico, entende-se que a escanção do discurso-enunciado toma como ponto de partida as coisas efetivamente ditas, cujo registro se faz de alguma maneira, em nosso caso, na assertiva formulada, através do significante inovação.

\section{a) Primeiro aspecto da questão: a noção corrente de inovação}

Sabe-se que esse termo carrega uma série de significados, que apontam a existência de ações, atividades, acontecimentos, processos, produtos, serviços, dispositivos que operam modificações e/ou transformações efetivas em determinadas situações, circunstâncias, modos de pensar e fazer existentes, já cristalizados e em uso, a exemplo das teorias e práticas tradicionais do ensinoaprendizagem, pautadas fundamentalmente na oratória, na leitura metódica de impressos, ou ainda, em imagens visuais clássicas, como o desenho, a pintura e, modernas, como a fotografia.

Considerando o debate atual sobre a questão da inovação educacional, notase uma tendência de vinculação do termo ao descobrimento e desenvolvimentos das 
assim chamadas novas tecnologias da informação e comunicação (TICs) aplicadas à educação. De fato, não se pode negar o caráter inovador de sua presença e funcionamento na gestão, produção e reprodução de saberes e conhecimentos na ordem social de nossos dias. Entretanto, existe um significado enviesado, correlacionado ao termo, que, ao fim e ao cabo, tende a concebê-lo de um modo relativamente reducionista.

Sobre isso, identifico, sumariamente, duas razões. A primeira consiste no desconhecimento do cultural como sendo em si mesmo inovador, criativo e produtivo. Pode-se dizer, nesse sentido, que o cultural carrega em si, no seu modo de ser cultura, as propriedades da inovação. Em função disso, entende-se que o modo de ser do cultural não tem nada de recente. A cultura é, precisamente assim, desde que passou a existir. Isso é o próprio da cultura, desde que o ser humano realizou os primeiros gestos, as primeiras ações que possibilitaram seu aparecimento, isto é, como algo não encontrado, dado, posto no ambiente natural.

Algo não feito por si, nem pelos complexos movimentos determinados pelas leis naturais, a exemplo de uma pedra transformada em faca; de um pedaço de madeira usado como ferramenta de caça; de uma porção de barro empregado como recipiente; de um pedaço de carvão natural ou pedra colorida servindo como lápis para rabiscar o chão e desenhar nas paredes das cavernas, não é obra da natureza. Todos esses acontecimentos e artefatos foram inovações que mudaram, de algum modo e em certa medida, o viver e o existir humano antigo.

Em segundo lugar, se for considerado, minimamente, o que tenho apresentado aqui acerca das noções de cultura, e, sobretudo, no que se refere a sua perspectiva clássica, ou seja, da cultura como sendo tudo aquilo que é produzido pelo ser humano, as TICs seriam apenas uma parcela desse universo. Nesse caso, o vínculo semântico entre o termo inovação e as TICs, condicionados única e exclusivamente por elas, seria reducionista, pois confunde a parte com o todo, e, em função disso, substitui o todo pela parte, erigindo, assim, o acontecimento singular das TICs como parâmetro definidor do significado do termo inovação.

Perder de vista que o cultural é, em si, inovador desde seu aparecimento, faz com que se embarque na ingenuidade da visão reducionista que concebe entusiasticamente as assim chamadas novas tecnologias como inovadoras, simplesmente 
por conta de serem novas, seja no seu gênero, seja nos seus usos. Tal entendimento, excluiria da noção de inovação, acontecimentos fundamentais de nossa história, que, não obstante aparente simplicidade, operaram mudanças significativas na vida das pessoas, a exemplo, do fogo utilizado para cozinhar, da roda para transportar, do arco e da flecha para caçar e do signo para comunicar.

Verifica-se que esse achado confere visibilidade a uma concepção, relativamente hegemônica, ou seja, a de se dizer algo sobre a 'inovação' vinculando, necessariamente, o termo e seus significados a referencias tecnológicas, relativamente recentes do mundo da cultura visual. Reduzindo, assim, o 'cultural' a determinados artefatos em detrimento de outros. Nesse sentido, a explicitação da concepção reducionista do significado corrente de inovação, não figura apenas como uma simples digressão retorica ou exercício de especulação interpretativa da semântica de seu significante; mas, ao contrário, como um achado importante da escavação empreendida, cujos desdobramentos e correlações acabam por conceber o artefato cultural visual do cinema e sua linguagem como inovadores, tão-somente pelo fato de serem invenções relativamente recentes da história das produções tecnológicas e visuais de nossa história.

b) Segundo aspecto da questão: o cinema como exemplo de 'inovação' cultural visual

Considerando os achados anteriores, observa-se que, indubitavelmente, o cinema aparece no desenrolar da história dos acontecimentos culturais visuais como uma dentre outras invenções inovadoras. Ele proporcionou um modo singular de capturar, produzir, mostrar e comunicar visualmente o que se pretende, deseja e interessa para o diretor e produtores cinematográficos. Entretanto, conforme já expus, essa visão não significa desmerecer, deslegitimar, desqualificar e excluir da composição semântica do significante 'inovação' as formas clássicas do desenho e da pintura, bem como a moderna fotografia, também como 'inovadoras'. Cada uma a seu modo operou rupturas e transformações nas maneiras de representar e significar o mundo; de registrá-lo e expressá-lo; de codificá-lo e projetá-lo, de dizer algo sobre alguma coisa.

Certamente, a relação homem-mundo, homem-pensamento e homemhomem não foram mais as mesmas desde o aparecimento do desenho, da pintura e 
da fotografia na ordem geral especifica do desenvolvimento da cultura visual. Com efeito, cada tem sua história, seu lastro, sua cartografia, não obstante esteja imbricada e implicada. Cada uma representa um legado peculiar na trajetória da produção cultural visual, não obstante, em algum ponto desse percurso, se encontre e se retroalimentem. Cada uma tem sua maneira de interferir no complexo das relações sociais, da produção e reprodução do capital, das formas de exercício do poder e dos modos de registrar, sistematizar, produzir e comunicar visualmente o saber e o conhecimento produzido, bem como ser coadjuvante no seu processo de produção.

Foi no ínterim desse movimento histórico da criatividade humana, que a imagem visual cinematográfica surgiu, instaurando um modo próprio de ser no sei da paisagem cultura visual; que operou rupturas e continuidades, desatou conexões clássicas no modo operandi de produção e comunicação visual; que estabeleceu novas relações entre as imagens visuais clássicas e as fotográficas, e destas com as virtuais; que acionou campos de saberes impensáveis e impossíveis de serem vinculados a outros gêneros visuais, corroborando, não somente a característica ontológica inovadora da cultura em geral, da cultura visual em particular, mas também e sobretudo, realizando inovações profundas na singularidade da cultura visual imagética clássicas e modernas.

Não é demais lembrar que esse processo não apareceu tão somente com as inovações virtuais, proporcionadas pelo desenvolvimento recente da microeletrônica e das ciências das informações e computacionais, que, sem dúvida, produziram avanços significativos na produção dos efeitos fantasmáticos apresentados, sobretudo, nos filmes ficcionais contemporâneos (CURRIE, 2005).

O cinema, não nos esqueçamos, foi uma invenção europeia, ocorrida no século XIX, profundamente devedora do avanço de ciências situadas fora do campo das humanidades e das visualidades, tais como a química e a física; bem como inegavelmente devedora do surgimento anterior da fotografia, dispositivo que operou, antes mesmo do cinema, uma espécie de ruptura entre o artefato visual produzido e os gestos clássicos de sua produção. Antes centrados, principalmente, na relação entre o olho e as habilidades das mãos dos desenhistas e pintores; com a fotografia, deslocado para o olho mediado pelo enquadramento da lente da máquina 
fotográfica (MARTIN, 2003; BRIGGS; BURKE， 2004; RAMOS， 2005; NÓVOA, 2009).

Sem querer retomar, aqui, as inúmeras características peculiares da linguagem cinematográfica e tão-somente tendo em vista ressaltar a ideia de inovação do cinema, basta-me assinalar que o cinema, sua linguagem e feitura operam rupturas significativas nos modos clássicos e modernos da produção da imagem visual e do que ela apresenta.

Refiro-me, aqui, especificamente, ao fato de que o artefato visual imagético do filme, diferentemente do desenho e do quadro de pintura, de um lado, depende não somente da criatividade e habilidades individuais do artista, mas de uma equipe. No final das contas, o filme parece como um produto que para existir depende de uma linha de montagem complexa e bem articulada que junta e conecta diferentes sujeitos e saberes, distintas habilidades, tempos e lugares, cenários e técnicas, suportes e tecnologias. Não é à toa que ao se falar do cinema sempre nos deparamos com a expressão indústria cultural do cinema.

De outro, o filme supera o desenho, a pintura e a fotografia por que ele não somente conseguiu sugerir o movimento mediante às imagens visuais produzidas, mas, ao contrário, ele desloca os significantes visuais. Põe, efetivamente, o que está parado, fixo em movimento. Movimento de tudo. Não somente dos personagens se deslocando de um lugar e tempo para o outro, de uma situação e circunstância para outras, mas também das coisas, das relações, das emoções, das ideologias, dos valores, dos sentidos de vida, das formações sociais e instituições, dos artefatos culturais e das práticas sociais, da vida e da morte, da fantasia e da existência. Parafraseando Marx, pode-se dizer que a solidez das coisas se desmancha no filme exposto na tela.

Ora, pelo exposto, não tem como deixar de reconhecer que o aparecimento e a consolidação efetiva do cinema, no cenário da cultura visual contemporânea, operou mudanças significativas, na logica cultural do capitalismo. Não tem como desconsiderar que ele figura como uma invenção tecnológico-cultural inovadora na paisagem mais ampla da cultura, irradiando e capilarizando-se, consequentemente, para outras esferas da sociabilidade atual, dentre estas a educação.

c) Terceiro aspecto da questão: o filme como inovação pedagógica 
Toquei, até aqui, em dois aspectos constituintes do objeto-enunciado em questão. Resta-me tratar a relação entre eles e a prática educativa escolar, o que pode ser formulado através da seguinte pergunta: o que se anuncia, quando se ventila a existência de um nexo entre cinema e educação escolar? Ou, mais precisamente, o que se diz acerca da incidência das possibilidades inovadoras do cinema na prática educativa escolar? A especifidade dessa pergunta configura o cerne do problema que motivou as problematizações realizadas nesse ensaio. Entretanto, sei que tal como está formulada, ela contempla um universo de possibilidades de respostas. Por isso, conforme já anunciei, contento-me em assinalar alguns pontos da questão, a fim de explicitar apenas o recorte de um feixe de relações, do conjunto geral que o objetoenunciado em análise contempla, composto por dois pontos significativos.

Em primeiro lugar, se semântica e argumentativamente a associação da palavra inovação aos termo cinema/filme e, destes, a educação, sugere que o filme seja um recurso tecnológico-cultural e didático-pedagógico inovador, a análise de uma série de discursos sobre esse acontecimento, no contexto da realidade educacional brasileira, não somente ratifica esse entendimento, como também aponta que ele não é algo dos nossos dias, pois o assunto tem circulado entre nós, brasileiros, desde o início do século passado.

Certamente, se considerarmos o cinema como uma invenção recente de nossa história, a discussão do uso de filmes educativos, no cenário brasileiro, não seria uma questão específica do século XXI, ou fins do século XX. Sobre isso, encontram-se evidências substantivas de que o assunto vem sendo objeto de interesse da sociedade (Decreto n ${ }^{\circ}$ 2.940/1928; Decreto nº 21.240/1932; VARGAS, 1934) e, em particular, de educadores brasileiros (ALMEIDA, 1931; SERRANO e VENÂNCIO, 1931; BARRETO, 1931; NORONHA, 1938), desde as primeiras décadas do século anterior, a partir da rubrica cinema educativo.

Embora o cinema não tenha sido descrito da mesma maneira como o fazemos hoje, verifica-se que outrora, ele fora não somente objeto de interesse de diferentes instâncias da sociedade, como também constata-se a emergência e a circulação de ideias acerca de seu potencial inovador para o trabalho educativo escolar, ou seja, já no início do século passado existia uma visão em voga que reconhecia o artefato cultural visual imagético fílmico como um dispositivo 
inovador capaz de proporcionar contribuições efetivas para a qualidade do ensino dos professores e da aprendizagem dos estudantes.

Esse achado, tanto histórico quanto discursivo, apresenta-se como relevante para o debate atual sobre o assunto do caráter inovador do cinema na educação, no que tange, especificamente, à desconstrução de uma visão ilusória da questão, uma visão sem passado. Esse achado desconstrói a visão ingênua e inocente de inovação, marcada por um presente sem rastro, que aparece por si. Visão alimentada pela moda ou hegemonia do discurso da inovação advinda do debate atual relativos as TICs.

Em segundo lugar, ao escandir os referidos escritos de época, indicados anteriormente, observei que o caráter inovador do cinema educativo incidiu não somente sobre a importância didática que ele teria para o trabalho escolar, mas também sobre seu impacto em outras esferas do fazer educativo. Dito de outra maneira, a noção de cinema educativo (SERRANO; VENÂNICO, 1931; BARRETO, 1932a; NORONHA, 1938; SALIBA, 2003) não se reduzira apenas ao caráter prático educativo. Ela listou, concomitantemente, as dimensões teórica e discursiva, como constituintes do modo de existir semântico da expressão inovação pedagógica escolar.

Nesse sentido, o esmiuçar dos matizes dessa noção apontou que a expressão cinema educativo correlacionava ao significante inovação pedagógica escolar, pelo menos três ordens de significados, a saber: a discursiva, a teórica e a operativa, as quais se articulavam, ou não, entre si, retroalimentando-se umas às outras.

$\mathrm{Na}$ ordem discursiva (ALMEIDA, 1931), o cinema educativo aparece como uma espécie de objeto-enunciado que sintetiza um campo de saber específico e possível, a partir do qual aparecem, se constituem uma série de dizeres, advindos de lugares distintos (TELAS; PALCOS, 1926; BRASIL. Decreto $n^{0}$ 21. 240, de 04 de abril de 1932), que evidenciam a existência de uma formação discursiva expressas em distintos modos de dizer algo sobre o objeto em questão: modos pedagógicos, jurídicos, políticos, policiais e religiosos ${ }^{3}$. Nesse caso, o acontecimento do cinema

\footnotetext{
${ }^{3}$ A propósito desse assunto, consultar: FAHEINA, Evelyn Fernandes Azevedo. $O$ discurso sobre o nexo pedagógico entre o cinema e a educação. 2015.169f. Tese (Doutorado em Educação) - UFPB, João Pessoa. em: <file://F:/Users/Admin/Downloads/EVELYN\%20FERNANDES\%20AZEVED0\%20FAHEINA.pdf>. Acesso em: 08 mar. 2019.
} 
educativo como inovação pedagógica escolar se encontra no nível ou limiar das coisas ditas, postas em circulação, assumidas, desejadas, ocultadas, dissimuladas, prescritas, normatizadas, teorizadas, silenciadas, proibidas, consumidas, distribuídas, empregadas, visualizadas, etc.

$\mathrm{Na}$ ordem teórica, a inovação pedagógica escolar do cinema educativo se constitui como um objeto da investigação de algum campo do saber elaborado, seja ele filosófico, teológico ou científico. Essa dimensão se faz presente, sobretudo, no debate realizado entre educadores e profissionais da área do cinema, ocupados em entender esse acontecimento específico do mundo da cultural visual cinematográfica e suas articulações com o trabalho educativo.

O caso da ordem teórica encontra-se registrado, por exemplo, em jornais, livros e revistas de época, que sistematizavam e fundamentam distintas concepções em voga a respeito da relação entre o cinema e a educação, e a luz de conhecimentos oriundos de diferentes domínios e em função de posições distintas do uso do cinema em espaços sociais de aprendizagem, tal como a escola, clubes e igrejas, que visavam explicitamente a formação social e cultural de seus participantes.

Do ponto de vista operativo (Barreto, 1932b), o emprego inovador do filme ganhou corpo na atividade concreta e cotidiana da escola, seja pelo incentivo do Estado, através da promulgação de algum ato legal sobre a matéria, seja de educadores e profissionais envolvidos, através da introdução do filme como uma mediação de seu fazer no processo do ensino e da aprendizagem. Nesse caso, o filme fora visto, concebido e empregado efetivamente como um recurso, um meio, um dispositivo didático que visava auxiliar o agir do ensinante no curso da realização de seu trabalho e do aprendente, no desenrolar de seus estudos, em face de problemas emergentes e regulares, sejam eles relativos ao entendimento de certos assuntos, ou ao desenvolvimentos de certos comportamentos e visões de mundo, diretamente relacionados ao contexto de suas existências históricas, cotidianas e situacionais. 


\section{Considerações finais}

Concluo as reflexões postas nesse ensaio, assinalando algumas séries enunciativas que atravessam a ordem de argumentação construída a partir de achados encontrados sobre o objeto-enunciado em questão.

A análise do caráter inovador do cinema na educação escolar apontou que a cultura carrega em si a propriedade da inovação, haja vista ser um acontecimento produzido pelo ser humano, profundamente distinto dos acontecimentos situados no mundo natural. O potencial inventivo e inovador do cultural se desdobra em todos os modos de existência da cultura, a exemplo dos processos, eventos e artefatos próprios da cultura visual e imagética.

Em função disso, foi possível identificar e explicitar o aparecimento do cinema e do artefato visual imagético fílmico como um divisor de águas, no transcurso do desenvolvimento da imagem visual. O modo peculiar da linguagem cinematográfica, operou rupturas significativas na maneira de se produzir e registrar o real e o imaginário, produziu efeitos profundamente distintos dos gerados pelas imagens clássicas do desenho, da pintura e da moderna fotografia, sobre seus receptores cinéfilos. Assim, pode-se entender que o complexo de características específicas do cinema, sintetizadas no filme, conferem inteligibilidade ao poder inovador e aos impactos no cenário da lógica do capital e das relações sociais vigentes da civilização da imagem.

A força inovadora do cinema atingiu profundamente os espaços sociais de aprendizagem, a exemplo da escola (DUARTE, 2002; COSTA, 2005; CABRERA, 2006; CATÉLLI, 2010 BRUZZO, 2004. No Brasil, por exemplo, esse acontecimento data do início do século XX, chegando aos nossos dias. Entretanto, verifiquei que o anúncio do cinema educativo, como uma inovação pedagógica, atingiu o pensar/dizer/fazer da atividade educativa escolar. Assim, enquanto dispositivo cultural visual imagético, o filme articulou de maneira exemplar e eficiente uma série de elementos de natureza epistemológica, cultural e social capazes de proporcionar uma aprendizagem intencionada e desejada, necessárias à 
experiência concreta do ensinar-aprender, situados nos contextos peculiares da escola.

Por fim, a análise aponta que o aparecimento do cinema, em geral, e do cinema educativo, em particular, desencadeou um conjunto de dizeres sobre a inovação pedagógica proporcionada pelo cinema, indicando a existência de uma formação discursiva, constituída por um complexo de relações entre ordens discursivas, teóricas e operativas. Quando as referidas ordens são transpostas de um ponto para outro, pode-se dizer que a inovação pedagógica escolar atravessou seus três limiares: o que se entende, se faz; o que se faz, entende-se; o que entende e se faz, justifica-se e se explica de modo peculiar. Tal formação discursiva aponta que dispomos de uma prática discursiva sobre o nexo entre cinema e educação, fundada na trilogia discurso-teoria-prática.

\section{Referências}

ALCANTARA, M. A. M.; CARLOS, E. J. Análise Arqueológica do Discurso: uma alternativa de investigação na Educação de Jovens e Adultos (EJA). Intersecções: revista de Estudos sobre Práticas Discursivas e Textuais, Jundiaí, v. 3, n. 5, p. 59-73, nov. 2013. Disponível em:

<http://www.anchieta.br/unianchieta/revistas/interseccoes/pdf/Interseccoes_Ano_6_N umero_3.pdf>. Acesso em: 20 dez. 2013.

ALMEIDA, J. C. M. O Cinema na Educação [Versão eletrônica]. Revista Escola Nova, v. 3, n. 3, p. 185-200, jun. 1931.

AUMONT, J. A imagem. Trad. Estela dos Santos Abreu e Cláudio César Santaro. ed. Campinas: Papirus, 1993. 320p.

AUMONT, J. et. al. (Orgs.). A estética do filme. Trad. Marina Appenzeller. 9. ed. Campinas: Papirus, 2012. 304p.

BARreto, S. F. Cinema Educativo. Revista Cinearte, v. 354, n. 30, dez, 1932a.

Disponível em: <http://memoria.bn.br/pdf/162531/per162531_1932_00354.pdf>. Acesso em: 10 jul. 2015.

BARreto, S. F. O Cinema e a Pedagogia. Revista Cinearte, v. 339, n. 32, jul. 1932b.

Disponível em: <http://memoria.bn.br/pdf/162531/per162531_1932_00339.pdf>. Acesso em: 10 jul. 2015.

BARTHES, R. Inéditos. vol. 3 - Imagem e moda. Trad. Ivone C. Beneetti. São Paulo: Martins Fontes, 2005. 384p. 
BRASIL. Decreto no 21. 240, de 04 de abril de 1932 (1932). Nacionaliza o serviço de censura dos filmes cinematográficos, cria a Taxa Cinematográfica para a educação popular e dá outras providências. Brasília, 1932. Disponível em: <http://www2.camara.leg.br/legin/fed/decret/1930-1939/decreto-21240-4-abril1932-515832-publicacaooriginal-81522-pe.html>. Acesso em: 02 abr. 2014 BRASIL. Decreto ñ 24.561, de 10 de julho de 1934 (1934). Cria, no Ministério da Justiça e Negócios Interiores, o Departamento de Propaganda e Difusão Cultural. Brasília, 1934. Disponível em: $<$ http://legis.senado.gov.br/legislacao/ListaNormas.action?numero=24651\&tipo_nor $\mathrm{ma}=\mathrm{DEC} \&$ data $=19340710 \&$ link $=\mathrm{s}>$. Acesso em:

BRASIL. Decreto n 1.949, de 30 de dezembro de 1939 (1939). Dispõe sobre o exercício de atividades de imprensa e propaganda no território nacional e dá outras providências. Brasília, 1939. Recuperado em 02 janeiro 2014, de http://presrepublica.jusbrasil.com.br/legislacao/126723/decreto-lei-1949-39\#par-1-art-124.

BRIGGS, Asa; BURKE, Peter. Cinema e televisão. In: Uma história social da mídia: de Gutemberg à internet. Trad. Maria Carmelita Pádua Dias. Rio de Janeiro: Jorge Zahar, 2004. p. $169-184$.

BRUZZO, C. (2004). Filme "Ensinante": o interesse pelo cinema educativo no Brasil. Revista Pro-posições, v. 15, n. 1, p. 1-15, 2004. Recuperado em de 12 junho, 2014, de https://www.fe.unicamp.br/pf-fe/43-artigos-bruzzoc.pdf.

CABRERA, J. O cinema pensa: uma introdução à Filosofia através de filmes. Trad. Rita Vinagre. Rio de Janeiro, RJ: Rocco, 2006. 400p.

CARLOS, E. J. (Org.). Educação e visualidade: reflexões, estudos e experiências pedagógicas com a imagem. João Pessoa: UFPB, 2008. 122p.

CARLOS, E. J. Por uma pedagogia crítica da visualidade. (Org.). João Pessoa: UFPB, 2010. 246p.

CARLOS, E. J.; VICENTE, D. do S. S. (Orgs.). A importância do ato de ver. João Pessoa, PB: UFPB, 2011. 184p.

CARLOS, E. J.; VICENTE, D. do S. S. Sobre o uso pedagógico da imagem fílmica na escola. Etd: Educação temática digital, v. 2, p. 546-565, 2017a. Disponível em: $<$ https://periodicos.sbu.unicamp.br/ojs/index.php/etd/article/view/8645247>. Acesso em: 20 mar. 2019. 
CARLOS, E. J.; VICENTE, D. do S. S. Achados sobre a noção arqueológica do discurso em Foucault. Revista Dialectus, ano 4, n. 11. ago.-dez. p. 176-191, 2017b. Disponível em: <http://www.periodicos.ufc.br/dialectus/article/view/31008>. Acesso em: 20 mar. 2019. CATÉLLI, R. E. Coleção de imagens: o cinema documentário na perspectiva da Escola Nova, entre os anos 1920 e 1930. Revista Educação \& Sociedade, v. 31, n. 111, p. 605-624, 2010. Disponível em: <http://www.cedes.unicamp.br>. Recuperado em: 10 jan. 2012.

COSTA, C. Educação, imagem e mídia. São Paulo: Cortez, 2005.

CURRIE, G. Ficções visuais. In: RAMOS, F. P. (Org.). Teoria contemporânea do cinema: pósestruturalismo e filosofia analítica. São Paulo: SENAC, 2005. p. 171-188.

DUARTE, R. Cinema \& educaşão. Belo Horizonte: Autêntica, 2002.

EISENSTEIN, S. O sentido do filme. Trad. Teresa Ottoni. Rio de Janeiro: Jorge Zahar, 2002. REVISTA CINEARTE. ano IV, n. 174, 1929. Disponível em: <http://memoria.bn.br/pdf/162531/per162531_1929_00174.pdf>. Acesso em: 10 jun. 2015.

ESCOSTEGUY, A. C. Estudos Culturais: uma introdução. In: SILVA, T. T. da. (Org.). O que é, afinal, Estudos Culturais? Belo Horizonte: Autêntica, 1999. p. 133-166.

FOUCAULT, M. A arqueologia do saber. Trad. Luiz Felipe Baeta Neves. 6. ed. Rio de Janeiro: Forense Universitária, 2000.

FORQUIN, J. Escola e cultura: as bases sociais e epistemológicas do conhecimento escolar. Trad. Guacira Lopes Louro. Porto Alegre: Artes Médicas, 1993.

FOUCAULT, M. As palavras e as coisas: uma arqueologia das ciências humanas. Trad. Salma Tannus Muchail. São Paulo: Martins Fontes, 1999. 544p.

HERNANDEZ, F. Catadores da cultura visual: proposta para uma nova narrativa educacional. Trad. Ana Death Duarte. Porto Alegre, RS: Mediação, 2007. 128p.

JAMESON, F. Pós-modernismo: a lógica cultural do capitalismo tardio. Trad. Maria Elisa Cevasco. São Paulo: Editora Atica, 1996.

LESSA, S. Para compreender a ontologia do ser social. 3. ed. ver. e ampl. Ijuí: UNIJUÍ, 2007. $240 \mathrm{p}$.

LUKÁCS, G. Prolegômenos para uma ontologia do ser social: questões de princípios para uma ontologia hoje tornada possível. Trad. Lya Luft e Rodnei Nascimento, São Paulo, SP: Boitempo, 2010.

LOURO, G. O cinema como pedagogia. In: LOPES, E. et al. (Orgs.). 500 anos de Educação no Brasil. Belo Horizonte: Autêntica, 2000. 
LUKÁCS, G. Prolegômenos para uma ontologia do ser social: questões de princípios para uma ontologia hoje tornada possível. Trad. Lya Luft e Rodnei Nascimento, São Paulo: Boitempo, 2010. 416p.

MARTIN, M. A linguagem cinematográfica. São Paulo, SP: Brasiliense, 2003. 184p.

NORONHA, J. P. (1938). Cinema Educativo. Revista Cinearte, v. 1, n. 484, 1938. Disponível em: <http://memoria.bn.br/pdf/162531/per162531_1938_00484.pdf>. Acesso em: 10 jul. 2015.

NOVOA, J.; FRESSATO, S. B.; FEIGELSON, S. (Orgs.). Cinematógrafo: um olhar sobre a história. São Paulo: UNESP; Salvador: EDUFBA, 2009. 496p.

PEIXOTO, A. Um sonho, um belo sonho. O Jornal, v. 5, 1929. Disponível em: <http://memoria.bn.br/DocReader/docreader.aspx?bib=110523_02\&pasta=ano $\% 201$ 92\&pesq=sonho $>$. Acesso em: 15 ago. 2015.

PINTO, Á. V. Teoria da cultura. In: Ciência e existência: problemas filosóficos da pesquisa científica. Trad. Maria Carmelita Pádua Dias. 2. ed. Rio de Janeiro: Paz e Terra, 1979.

p. 119-138.

RAMOS, F. P. (Org.). Teoria contemporânea do cinema: pós-estruturalismo e filosofia analítica. v. 1. São Paulo: SENAC, 2005. 436p.

SANTAELLA, L.; NOTH, W. As imagens podem mentir? In: Imagem: cognição, semiótica e mídia. 4. ed. São Paulo: Iluminuras, 2005. p. 195-208.

SCHULMAN, N. O center Contemporary Cultural Studies da Universidade de Birmingham: uma história intelectual. In: SILVA, T. T. da. (Org.). O que é, afinal, Estudos Culturais? Belo Horizonte: Autentica, 1999. p. 167-224.

SALIBA, M. E. F. Cinema contra cinema: o cinema educativo de Canuto Mendes (1922 - 1931). São Paulo: Annablume, 2003.

SANTOS, B. S. Pelas mãos de Alice: o social e político na pós-modernidade. 2. ed. São Paulo: Cortez, 1996.

SERRANO, J., \& VENÂNCIO F. O cinema Educativo [Versão eletrônica]. Revista Escola Nova, v. 3, n. 3, p. 154-184, 1931.

SILVA, T. T. (Org.). O que e afinal, Estudos Culturais? Belo Horizonte: Autêntica, 1999.

TELAS \& PALCOS. Jornal Correio da Manbã, v. 7, 1926. Disponível em: <http://memoria.bn.br/DocReader/docreader.aspx?bib=089842_03\&pasta=ano\%20192 \&pesq=igreja $>$. Acesso em: 15 ago. 2015.

THOMPSON, J. B. Ideologia e cultura moderna: teoria social crítica dos meios de comunicação de massa. Petrópolis: Vozes, 1995. 432p. 
VARGAS, G. D. O cinema nacional, elemento de aproximação dos habitantes do país - discurso pronunciado na manifestação promovida pelos cinematografistas. 1934. Disponível em: $<$ http://www.biblioteca.presidencia.gov.br/ex-presidentes/getulio-vargas/discursos1/1934/04.pdf/view>. Acesso em: 12 fev. 2014.

RECEBIDO: $26 / 03 / 2019$

RECEIVED: 03/26/2019

RECIBIDO: 26/03/2019

APROVADO: 24/05/2019

APPROVED: 05/24/2019

APROBADO: 24/05/2019 